\title{
VENLAFAXINE ER-RELATED STRONG SUICIDAL INTENT IN AN ADULT WITH LITHIUM-TREATED SEVERE MAJOR DEPRESSION: A PHENOMENOLOGICAL PROXIMITY WITH OTHER PARADOXICAL REACTIONS OF PSYCHOACTIVE AGENTS
}

\author{
Udo Bonnet $^{1,2}$ \& Uwe Knierim ${ }^{1}$ \\ ${ }^{I}$ Department of Psychiatry, Psychotherapy and Psychosomatic Medicine, Evangelisches Krankenhaus Castrop-Rauxel, \\ Academic Teaching Hospital of the University of Duisburg/Essen, Castrop-Rauxel, Germany \\ ${ }^{2}$ LVR Hospital Essen, Department of for Psychiatry and Psychotherapy, Medical Faculty, \\ University of Duisburg-Essen, Essen, Germany
}

received: 3.6.2019;

revised: 23.8.2019;

accepted: 30.8 .2019

$* * * * *$

\section{INTRODUCTION}

Suicidality can be differentiated into definite suicidal behavior, suicidal ideation, plan and suicidal intent, the "subjective expectation and desire for a self-destructive act to end in death" (APA 2003). Applying antidepressants $(\mathrm{AD})$ to children and adolescents have been shown to be associated with a paradoxical burgeoning of suicidality (Hetrick et al. 2012). According to this Cochrane review including young population with major depressive disorders (MDD), there was an increased risk $(58 \%)$ of suicide-related outcome for those on $\mathrm{AD}$ compared with a placebo (relative risk 1.58; 95\% CI 1.02 to 2.45) (Hetrick et al. 2012). In 2014, a large British cohort study confirmed a significant positive relationship between the use of different ADs and the risk of suicide in adult MDD-patients (Coupland et al. 2015). To precise, absolute risks of attempted suicide or self-harm over one year ranged from $1.02 \%$ for amitriptyline, $1.41 \%$ for sertraline, $1.61 \%$ for escitalopram, $2.64 \%$ for trazodone, $2.55 \%$ for mirtazapine to $2.96 \%$ for venlafaxine (Coupland et al. 2015). In this context, there is a vigorous debate about whether and how AD can trigger suicidality in various age groups (Mihanović et al. 2010, Goldsmith \& Moncrieff 2011, Nischal et al. 2012, Fornaro et al. 2019). Here, we describe the shift from chronic suicidal ideation to compulsive suicidal intent during an augmentation treatment using venlafaxine-extended release (ER) in an adult MDDpatient under pharmacotherapy with lithium, mirtazapine and L-thyroxin.

\section{CASE PRESENTATION}

A 45-year-old white male with normal BMI was admitted due to a severe relapse of a recurring MDD, which occurred under lithium (serum level: $0.82 \mathrm{mM}$ ) and $45 \mathrm{mg}$ mirtazapine, both taken at bedtime, together with frequent medical/psychiatric counselling \& psycho- education as well as long-term psychotherapy. Comorbid alcohol use disorder and social phobia were in remission in contrast to an active autoimmune polyglandular syndrome (APS) subtype 4 with vitiligo acrofacialis, Hashimoto thyroiditis and lymphocytic colitis (Betterle et al. 2014). Beyond this, the physical examination was unremarkable. Routine lab revealed an increased thyroid-stimulating hormone (TSH $25 \mathrm{mU} / \mathrm{L}$ ) despite thyroid-hormone-replacement therapy with $200 \mu \mathrm{g} /$ day L-thyroxine and a slightly increased CRP. The remaining lab was normal including vitamin $\mathrm{B}$ serum-levels and autoimmune diagnostics even with respect to Addison's disease and diabetes mellitus (Betterle et al. 2014). Upon admission, the patient was severely depressed (Hamilton Depression Score; HAMD21item 39 points) with dominant loss of energy, social withdrawal, loss of appetite, great lacks of drive and motivation, feeling of worthlessness, great difficulty to concentrate, diffuse anxious agitation, high stress vulnerability, insomnia and chronic suicidal ideation (APA 2003). Initially, the patient was relaxed by lorazepam $0.5 \mathrm{mg}$ q.i.d. in parallel to an augmentation with venlafaxine-ER, which was established stepwise from $37.5 \mathrm{mg}$ /day up to $225 \mathrm{mg}$ /day within three weeks. At $150 \mathrm{mg}$ venlafaxine-ER/day, the patient reported a partial improvement of mood, concentration, insomnia, appetite and motivation (HAMD21item 24 points) but developed strong impulse and desire for suicide by jumping from a height which was accompanied by further adverse effects (restlessness, anxiety, sweating, hand jitter) (Sinclair et al 2009). He was deeply irritated because he had never experienced a similar compulsive quality of suicidality before. The urge to suicide was dose-dependent, since increasing from $150 \mathrm{mg} / \mathrm{d}$ to $225 \mathrm{mg}$ /day venlafaxine-ER and then, completely disappearing after tapering off venlafaxineER. The same applied to the accompanying jitteriness/ anxiety and sweating which was controlled by lorazepam for PRN-medication - just as the strong suicidal 
intent. Thereafter, the daily lorazepam relaxation $(0.5 \mathrm{mg}$ q.i.d.) was gradually discontinued. Within the next 6 weeks of multimodal inpatient treatment (psycho-, occupational-, movement-, milieu-therapy), the MDD gradually remitted (down to HAM-D21item 6 points) (Zajecka 2003) without venlafaxine or any other pharmacological augmentation-strategy. Simultaneously, the suicidal thoughts, which persisted with varying severity for several years before, lost its intensity up to discharge. In addition, concurrent to an increasing stress tolerance, the vitiligo faded slightly and the patient became spontaneously euthyroid even without an escalation of thyroid hormone-replacement. This course of the augmentation with venlafaxine-ER was rather surprising for us because the patient had a combined treatment with venlafaxine-ER (up to $300 \mathrm{mg} / \mathrm{day}$ ), L-thyroxin and mirtazapine a few years ago, however, not together with lithium and not complicated by a worsening of suicidality.

At discharge, we reviewed the treatment together with the patient and asked him again for any psychosocial event that might have promoted the suicidal intent independent on increasing the venlafaxine dose. He denied this again and underlined that the suicidal intent had exclusively emerged along with the venlafaxine dose-escalation. He could exclude that the accompanying adverse effects (jitteriness/anxiety; sweating) had amplified his suicidality or that he wanted to end his life as a consequence of being more activated.

\section{DISCUSSION}

Indeed, lithium reduces suicide risk (Sadkowski et al. 2013, Tondo \& Baldessarini 2018). The exact mechanism, however, remains obscure as yet, eventually involving the modulation of the monoamine neurotransmission system from intracellular, the strengthening of the cellular oxidative stress defense and a limbic glutamate surge (Sadkowski et al. 2013, Machado-Vieira et al. 2015, 2017, Szulc et al. 2018) all, by the way, by analogy with ketamine (Weckmann et al. 2017, Bonnet 2017a). There is convincing evidence that alterations of the brain serotonin-allostasis are involved in the generation of suicidal behavior (Sadkowski et al 2013, van Heeringen \& Mann 2014). We also assume a change in the balance in the orchestra of susceptible serotonin receptor-subtypes to be responsible for the venlafaxine-induced progression from suicidal ideation to suicidal intent in our case presentation. Such sensitivity-changes in receptor signaling are not unusual in the long-term stimulation or under-stimulation of neurotransmitter brain networks and most likely underlay paradoxical adverse reactions, citing e.g. the cannabis hyperemesis syndrome (Bonnet 2014b), opioidinduced hyperalgesia (Johnson et al. 2013), analgesicinduced headache (Johnson et al 2013), neurolepticinduced catatonia (Lee 2010) and, perhaps, the drift from ketamine's favorable antidepressant and anti-suicidal response to addiction-related dysphoria and suicidality (Jansen 2000, Bonnet 2017a). A more common hypothesis of the amplification of suicidality during the titration of ADs relies on their activating effects including akathisia and jitteriness, but this has not been evaluated by controlled studies so far (Sinclair 2009, Goldsmith \& Moncrieff 2011). The patient himself did not claim such a functional relation with his suicidal intent although it cannot be totally excluded that unpleasant emotions accompanying the venlafaxine-related adverse effects had been unconscious cues or incentives for his increase in suicidality.

\section{Acknowledgements:}

We would like to thank the patient who gave us his written informed consent to introduce his case here.

\section{Conflict of interest: None to declare.}

\section{Contribution of individual authors:}

Udo Bonnet: concept, manuscript writing, literature search.

Uwe Knierim: manuscript revising, literature search.

\section{References}

1. American Psychiatric Association: Practice guideline for the assessment and treatment of patients with suicidal behaviors. Am J Psychiatry 2003; 160(11 Suppl):1-60

2. Betterle C, Garelli S1, Coco G, Burra P. A rare combination of type 3 autoimmune polyendocrine syndrome (APS-3) or multiple autoimmune syndrome (MAS-3). Auto Immun Highlights 2014; 5:27-31

3. Bonnet $U$ : How much alcohol is in ketamine's antidepressant action? Life Sci 2017a; 168:54-57

4. Bonnet U: Chapter 48: Cannabis Hyperemesis Syndrome. In: Handbook of Cannabis and Related Pathologies (1st Edition) - Biology, Pharmacology, Diagnosis, and Treatment Reviews, Editor: Victor Preedy; Elsevier, Academic Press 2017b; p. 466-470

5. Coupland C, Hill T, Morriss R, Arthur A, Moore M, Hippisley-Cox J: Antidepressant use and risk of suicide and attempted suicide or self harm in people aged 20 to 64: cohort study using a primary care database. BMJ 2015; $350: h 517$

6. Fornaro M, Anastasia A, Valchera A, Carano A, Orsolini $L$, Vellante $F$, Rapini $G$, Olivieri L, Di Natale S, Perna G, Martinotti G, Di Giannantonio M, De Berardis D: The FDA "Black Box" Warning on Antidepressant Suicide Risk in Young Adults: More Harm Than Benefits? Front Psychiatry 2019; 10:294

7. Goldsmith L, Moncrieff $J$ : The psychoactive effects of antidepressants and their association with suicidality. Curr Drug Saf 2011; 6:115-21

8. Hetrick SE, McKenzie JE, Cox GR, Simmons MB, Merry $S N$ : Newer generation antidepressants for depressive disorders in children and adolescents. Cochrane Database Syst Rev 2012; 11:CD004851 
9. Jansen KL: A review of the nonmedical use of ketamine: use, users and consequences. J Psychoactive Drugs 2000; 32:419-33

10. Johnson JL, Hutchinson MR, Williams DB, Rolan P. Medication-overuse headache and opioid-induced hyperalgesia: A review of mechanisms, a neuroimmune hypothesis and a novel approach to treatment. Cephalalgia 2013; 33:52-64

11. Lee JW: Neuroleptic-induced catatonia: clinical presentation, response to benzodiazepines, and relationship to neuroleptic malignant syndrome. J Clin Psychopharmacol 2010: 30:3-10

12. Machado-Vieira R, Gattaz WF, Zanetti MV, De Sousa RT, Carvalho AF, Soeiro-de-Souza MG, Leite CC, Otaduy MC: A Longitudinal (6-week) 3T (1)H-MRS Study on the Effects of Lithium Treatment on Anterior Cingulate Cortex Metabolites in Bipolar Depression. Eur Neuropsychopharmacol 2015; 25:2311-7

13. Machado-Vieira R, Zanetti MV, Otaduy MC, De Sousa $R T$, Soeiro-de-Souza MG, Costa AC, Carvalho AF, Leite CC, Busatto GF, Zarate CA Jr, Gattaz WF: Increased Brain Lactate During Depressive Episodes and Reversal Effects by Lithium Monotherapy in Drug-Naive Bipolar Disorder: A 3-T 1H-MRS Study. J Clin Psychopharmacol 2017; 37:40-45

14. Mihanović M, Restek-Petrović B, Bodor D, Molnar S, Oreskovic A, Presecki P: Suicidality and side effects of antidepressants and antipsychotics. Psychiatr Danub 2010; 22:79-84
15. Nischal A, Tripathi A, Nischal A, Trivedi JK: Suicide and antidepressants: what current evidence indicates. Mens Sana Monogr 2012; 10:33-44

16. Sadkowski M, Dennis B, Clayden RC, Elsheikh W, Rangarajan S, Dejesus J, Samaan Z: The role of the serotonergic system in suicidal behavior. Neuropsychiatr Dis Treat 2013; 9:1699-716

17. Sinclair LI, Christmas DM, Hood SD, Potokar JP, Robertson A, Isaac A, Srivastava S, Nutt DJ, Davies SJ: Antidepressant-induced jitteriness/anxiety syndrome: systematic review. Br J Psychiatry 2009, 194:483-90

18. Szulc A, Wiedlocha M, Waszkiewicz N, Galińska-Skok B, Marcinowicz P, Gierus J, Mosiolek A: Proton magnetic resonance spectroscopy changes after lithium treatment. Systematic Review. Psychiatry Res Neuroimaging 2018; 273:1-8

19. Tondo L, Baldessarini RJ: Antisuicidal Effects in Mood Disorders: Are They Unique to Lithium? Pharmacopsychiatry 2018; 51:177-188

20. Weckmann K, Deery MJ, Howard JA, Feret R, Asara JM, Dethloff $F$, Filiou MD, Iannace $J$, Labermaier $C$, Maccarrone G, Webhofer, Teplytska L, Lilley K, Müller $M B$, Turck CW: Ketamine's antidepressant effect is mediated by energy metabolism and antioxidant defense system. Sci Rep 2017; 7:15788

21. van Heeringen $K \&$ Mann JJ: The neurobiology of suicide, Lancet Psychiatry 2014; 1:63-72

22. Zajecka JM: Treating depression to remission. J Clin Psychiatry 2003; 64(Suppl 15): 7-12

Correspondence:

Prof. Udo Bonnet, $M D$

Department of Psychiatry, Psychotherapy and Psychosomatic Medicine,

Evangelisches Krankenhaus Castrop-Rauxel

44577 Castrop-Rauxel, Germany

E-mail:udo.bonnet@uni-due.de 